http://dx.doi.org/10.18675/1981-8106.vol26.n51.p167-182

\title{
Refletindo Sobre o PIBID em Tempos de Desprofissionalização Docente
}

\author{
Reflecting About PIBID in Times of Deprofessionalization Teacher
}

\section{Reflexionando Sobre el PIBID en Tiempos de Desprofesionalización Docente}

\section{Carla Patrícia Quintanilha Corrêa'}

IInstituto Superior de Educação Professor Aldo Muylaert (ISEPAM), Rio de Janeiro - Brasil. E-mail: carlapqcorrea@hotmail.com

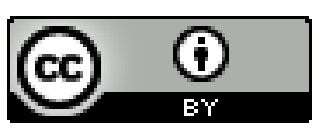

Educação: teoria e prática, Rio Claro, SP, Brasil - eISSN: 1981-8106

Está licenciada sob Licença Creative Common

\section{Resumo}

O trabalho aborda o contexto atual da docência no país, destacando as dificuldades enfrentadas pelos professores no exercício da sua profissão, geradas pelas políticas educacionais voltadas às avaliações externas. Diante disto, muitos professores vêm sentindo a perda da autonomia e identidade profissional, resultando no fenômeno da desprofissionalização docente. Objetiva-se refletir sobre a política pública de incentivo à formação inicial de professores, o PIBIB (Programa Institucional de Bolsa de Iniciação à Docência), no contexto atual de desprofissionalização docente. Para isto, apresenta-se uma reflexão teórica, baseada em Françoise Lantheaume, Claude Lessard, Christian Maroy, Marli André, Bernadete Gatti, Dalila Oliveira, Isabel Lelis, dentre outros autores. Aponta-se que o PIBID, ainda que seja uma política vinculada ao Índice de Desenvolvimento da Educação (IDEB), pode fomentar a formação inicial de professores em uma perspectiva crítica.

Palavras-chave: formação inicial de professores; desprofissionalização docente; PIBID 


\begin{abstract}
The paper discusses the current context of teaching in the country, highlighting the difficulties faced by teachers in the exercise of their profession, generated by educational policies geared to external evaluations. Given this, many teachers have felt the loss of autonomy and professional identity, resulting in the teaching deprofessionalization phenomenon. The objective is to reflect on public policy to encourage initial teacher education, the PIBIB (Institutional Program Initiation Purse in Teaching), in the current context of teaching deprofessionalization. For this, we present a theoretical reflection based on Françoise Lantheaume, Claude Lessard, Christian Maroy, Marli André, Bernadete Gatti, Dalila Oliveira, Isabel Lelis, among other authors. It points out that the PIBID, although it is a policy linked to the Education Development Index (IDEB), can promote the initial training of teachers in a critical perspective.
\end{abstract}

Keywords: teacher deprofessionalization; initial teacher training; PIBID

\title{
Resumen
}

El trabajo aborda el contexto actual de la docencia en el país, destacando las dificultades enfrentadas por los profesores en el ejercicio de su profesión, dificultades generadas por las políticas educacionales dirigidas a las evaluaciones externas. Ante esto, muchos profesores vienen sintiendo la pérdida de autonomía e identidad profesional, resultando en el fenómeno de desprofesionalización docente. El trabajo tiene como objetivo reflexionar sobre la política pública de incentivo a la formación inicial de profesores, el PIBIB (Programa Institucional de Bolsa de Iniciação à Docência*), en el contexto actual de desprofesionalización docente. Para esto, se presenta una reflexión teórica, basada en Françoise Lantheaume, Claude Lessard, Christian Maroy, Marli André, Bernadete Gatti, Dalila Oliveira, Isabel Lelis, entre otros autores. Se señala que el PIBID, a pesar de ser una política vinculada al Índice de Desarrollo de la Educación (IDEB), puede fomentar la formación inicial de profesores en una perspectiva crítica.

\section{* PIBID: Programa Institucional de Becas de Iniciación a la Docencia.}

Palabras clave: formación inicial de profesores; desprofesionalización docente; PIBID

\section{Introdução}

A docência enfrenta tempos turbulentos nos dias atuais. Pesquisas revelam que, em diferentes lugares do mundo, ser professor tem se tornado tarefa difícil e até mesmo pouco atrativa, devido ao contexto profissional vivenciado pelos professores (MAROY, 2006; 
OLIVEIRA, 2010; LELIS, 2012; GATTI, 2010).

Intensificam-se as políticas educacionais visando apenas resultados do processo de ensino-aprendizagem, aferidos por avaliações externas realizadas no âmbito da educação básica e do ensino superior. Esta ênfase nos resultados tem trazido sérias consequências aos profissionais da educação, especialmente aos professores, e também aos alunos (LANTHEAUME, 2012; LELIS, 2012).

Neste contexto, ressalta-se uma política pública que vem se destacando nos cursos de licenciatura do país, o PIBID (Programa Institucional de Bolsa de Iniciação à Docência) (GATTI et al., 2014). Em tempos de desprofissionalização docente (MAROY, 2006; OLIVEIRA, 2010), o PIBID parece apresentar uma contradição a ser enfrentada por seus participantes: de um lado pode fomentar a formação inicial de professores, mobilizando seus saberes em situação, mas, de outro, pode explicitar a demanda das escolas por "ajuda" no reforço escolar de seus alunos, a fim de melhorar seus resultados em avaliações externas (ROCHA, 2012).

Diante deste cenário, este artigo consiste em uma reflexão teórica que objetiva problematizar o PIBID no contexto atual da docência, destacando o fenômeno da desprofissionalização docente.

Para isto, no primeiro momento do artigo, apresenta-se o contexto atual da docência. Após, aponta-se o PIBID como uma das políticas de formação docente do país. E, por fim, discute-se o PIBID em tempos de desprofissionalização docente, sinalizando indicativos de que a participação no programa pode auxiliar no entendimento desta questão. Espera-se, por meio desta reflexão, contribuir ao debate da docência na contemporaneidade.

\section{Contexto Atual da Docência}

Os professores têm enfrentado um contexto de mudanças no exercício de sua profissão. Maroy (2006, p. 111) enfatiza que “(...) además de sus tareas tradicionales de preparación de clases, de docencia y de evaluación, los docentes tienen que participar cada vez más a la vida de su escuela, implicarse en un trabajo colectivo, formarse..." As expectativas em relação à atividade do professor referem-se ao melhor desempenho profissional, o que resultaria em melhores resultados nas avaliações realizadas pelos alunos.

A concorrência do mundo do trabalho atual requer trabalhadores preparados para lidar com o contexto de mudanças em que vivemos. $\mathrm{O}$ trabalhador não pode mais prescindir de conhecimentos básicos sobre como aprender novas tarefas, habilidades e formas de atuação. Requer-se a capacidade de aprender a aprender.

Os mercados mundiais constataram que a escola de hoje não tem conseguido 
responder aos anseios de formação do trabalhador requerido, aumentando a pressão sobre os governos quanto à garantia de uma educação que corresponda aos novos tempos.

De fato, os Estados compreenderam que sua economia não tem muita coisa a oferecer a pessoas pouco escolarizadas: logo, para permanecer competitivo, é preciso investir numa mão-de-obra altamente qualificada e capaz de aprender coisas novas ao longo de sua vida profissional (LESSARD, 2006, p. 202).

Diante disto, a escolarização tem se tornado grande preocupação dos governos no sentido de buscar formas de garantir uma mão de obra adequadamente preparada para atuar no mercado de trabalho, uma vez que “(...) os Estados entenderam que os custos sociais, econômicos e políticos da subescolarização ou de uma escolarização inadequada e de má qualidade são altos demais" (LESSARD, 2006, p. 203).

Buscando o desenvolvimento econômico, várias políticas educacionais foram lançadas, baseadas nos resultados das avaliações externas, responsabilizando as escolas por seu desempenho, suscitando a reação do professorado diante de tantas inovações. Acentuamse formas de distanciamento ou de oposição a estas reformas, uma vez que resultam no fenômeno conhecido como desprofissionalização docente (MAROY, 2006).

Segundo Oliveira (2010), a desprofissionalização docente pode ser entendida como um processo de perda da identidade profissional.

Nessa perspectiva, os trabalhadores da educação estariam sofrendo processos de desprofissionalização por diversos fatores que variam desde a padronização dos meios de trabalho e introdução de tecnologias educativas em larga escala nas escolas até a deslegitimação dos seus saberes específicos resultante dos efeitos produzidos pelas avaliações externas que dão publicidade aos resultados vinculando o baixo rendimento dos alunos com o desempenho profissional dos docentes (OLIVEIRA, 2010, p. 26).

Para Maroy (2006), diante deste quadro, o professor tem afetada a sua identidade profissional, uma vez que se divide entre as expectativas oficiais para sua atuação, com foco nas habilidades técnicas e gerenciais, e as suas próprias expectativas quanto ao exercício do ofício, voltadas à dimensão emocional, à concepção de arte na tarefa educativa.

A tensão criada entre estes dois polos bem presentes no exercício profissional tem levado muitos professores a experimentarem um sentimento de desqualificação e desprofissionalização, com o comprometimento da autonomia e da realização, além da perda do status social e profissional (MAROY, 2006). 
Isto acontece porque, no contexto atual, o trabalho docente tem se intensificado, tornando-se mais complexo. "La intensificación se señala más por un peso mayor y una extensión de las tareas que realizar y por una complicación del trabajo en clase que por una prolongación del tiempo de trabajo" (MAROY, 2006, p. 111).

De acordo com Lelis (2012, p. 155), a intensificação do trabalho docente está ligada "especialmente na gestão da sala de aula, exigindo o desenvolvimento de competências para além do domínio de conhecimentos e habilidades". Assim, os professores precisam lidar com as expectativas dos pais dos alunos e das instâncias superiores que coordenam a escola, a fim de conseguir realizar seu trabalho, atendendo às expectativas de desempenho relacionadas àquela escola específica. Esta realidade cotidiana tem gerado dificuldades para os professores, muito mais ligadas ao seu ambiente de trabalho do que a transtornos pessoais (LANTHEAUME, 2012).

Para Lantheaume (2012, p. 373), "no estado de "desassossego" permanente que se tornou a marca do ofício de professor, os profissionais encontram soluções para os problemas a que estão expostos." Assim, vão sendo criadas certas estratégias de enfrentamento das dificuldades encontradas no exercício do ofício: resistência a algumas tarefas, distanciamento diante dos problemas da prática, conformar-se com uma situação problemática, períodos de menor intensidade no trabalho para proteger-se de sobrecarga, dentre outras (LANTHEAUME, 2012).

Para as políticas educacionais atuais, a figura do professor aparece como central na preparação da mão-de-obra para o mercado de trabalho, daí a ênfase na formação docente, tanto inicial como contínua.

Nesta perspectiva, Lessard (2006) conclui:

Em suma, essa exigência de uma mão-de-obra docente de melhor qualidade é claramente e cada vez mais um assunto de Estado que, pelo viés de políticas explicitamente voltadas para este objetivo, tenta coordenar o conjunto dos atores do campo do ensino, garantir a coerência e a sinergia de suas ações e inseri-los no âmbito mais global das políticas educativas focadas na economia do saber, na globalização da concorrência e na ética da responsabilização e do desempenho. Essa política de Estado procura não apenas vincular melhor, mas, se possível, alinhar os universos da formação inicial e do desenvolvimento profissional com as orientações de políticas educativas para a educação básica, por um lado, e as do ensino superior, pelo outro (LESSARD, 2006, p. 203-204).

Assim, este contexto desfavorável à profissão também afeta os cursos de formação de professores. Os alunos que se decidem pela docência, muitas vezes, mostram-se desanimados com o panorama atual enfrentado pelos professores nas escolas. Tendo em vista tal situação, o governo federal implementou uma série de iniciativas incentivadoras da formação de 
professores, tanto inicial como contínua, visando não apenas o incentivo à docência, mas também a melhoria da educação brasileira. Neste trabalho, atenta-se especialmente a uma das políticas de formação inicial de professores, o PIBID (Programa Institucional de Bolsa de Iniciação à Docência), abordado a seguir.

\title{
3 Políticas de Formação Inicial de Professores: o PIBID
}

Segundo Gatti, Barreto e André (2011), quando se trata do tema formação e políticas docentes, deve-se atentar a duas preocupações:

\begin{abstract}
Por um lado, que não se deixe de investigar a formação inicial, que ainda carece de muito conhecimento sobre como formar professores competentes para atuar no mundo atual; por outro lado, as pesquisas não podem correr o risco de reforçar uma ideia, corrente no senso comum, de que o(a) professor(a) é o único elemento no qual se deve investir para melhorar a qualidade da educação (GATTI, BARRETO, ANDRÉ, 2011, p. 15).
\end{abstract}

Obviamente, outros fatores são imprescindíveis à docência, como as condições de trabalho, os salários, a infraestrutura das escolas, dentre outros, que uma vez não priorizados nas pautas do poder público, resultarão em dificuldades no cotidiano escolar.

Em relação à formação inicial, pesquisas apontam dificuldades nos cursos de licenciatura (GATTI, 2010; 2014), lançando mais responsabilidade para os processos de formação contínua como meio de reverter tal situação.

De acordo com Gatti, Barreto e André (2011), pode-se dizer que:

[...] há uma crise na formação inicial de professores para a educação básica, tal como normatizada e oferecida pelas IESs, especialmente em seus aspectos de dinâmica curricular, aí incluídos os estágios, tanto nos cursos presenciais como nos a distância. A fragmentação formativa é clara, as generalidades observadas nos conteúdos curriculares também (GATTI, BARRETO, ANDRÉ, 2011, p. 259).

Neste sentido, algumas iniciativas do governo federal objetivam intervir nesta situação, melhorando a formação inicial de professores no país, como a Universidade Aberta do Brasil (UAB) e o Pró-Licenciatura, que utilizando a metodologia da educação à distância tem oferecido formação em nível superior em diversas áreas (UAB) e também atuando na formação de professores, especialmente daqueles que já exercem a docência na educação 
básica pública (Pró-Licenciatura); o Plano Nacional de Formação de Professores de Educação Básica (PARFOR), modalidade presencial de primeira ou segunda licenciatura, direcionada exclusivamente a professores em exercício na rede pública da educação básica; o Programa Institucional de Bolsa de Iniciação à Docência (PIBID), que objetiva incentivar a iniciação à docência, funcionando como estímulo à formação inicial ao conceder bolsas aos licenciandos para atuarem em escolas de educação básica.

Estas iniciativas do governo federal voltadas à formação inicial de professores constituem rico tema de pesquisas na área de educação na ponderação dos limites e possibilidades de cada uma das iniciativas. Devido à brevidade desta proposta, busca-se refletir sobre uma das políticas de formação inicial de professores, o PIBID (Programa Institucional de Bolsa de Iniciação à Docência). Propõe-se a reflexão sobre o PIBID no contexto da desprofissionalização do trabalho docente vivenciado hoje nas escolas brasileiras.

De acordo com o Relatório de Gestão da Diretoria de Formação de Professores da Educação Básica (DEB)- 2009 a 2013, o Programa Institucional de Bolsa de Iniciação à Docência (PIBID) foi lançado em 2007 (BRASIL, 2013a), no âmbito da Coordenação de Aperfeiçoamento de Pessoal de Nível Superior (CAPES). Sua finalidade consiste no estímulo à docência, a fim de aperfeiçoar a formação inicial de professores e, desta forma, contribuir para o desenvolvimento da educação brasileira.

O programa funciona a partir de bolsas concedidas a licenciandos para que exerçam atividades pedagógicas junto a alunos das escolas públicas de educação básica, tendo como responsáveis por esta ação um professor do seu curso de licenciatura e um professor da unidade escolar para a qual foi designado. Estes professores também recebem uma bolsa.

Para que a instituição de nível superior faça parte do programa, deve ser enviado um projeto à CAPES, contendo seu plano de ações propostas, visando alcançar os objetivos estipulados pelo Ministério da Educação (MEC). O projeto será avaliado e uma vez aprovado pela CAPES, a instituição passa a fazer parte do PIBID.

Deve haver um professor da licenciatura especificamente responsável pelo acompanhamento do projeto enviado, tornando-se o coordenador institucional do PIBID na instituição de ensino superior (IES), recebendo bolsa. Em 2010, a portaria no 260 da CAPES adiciona outra modalidade de bolsa para o coordenador de área de gestão de processos educacionais, um professor da licenciatura responsável por auxiliar o coordenador institucional na gestão do projeto na IES.

O aluno da licenciatura terá carga horária de 30 horas mensais de dedicação ao programa (BRASIL, 2010b) e, de acordo com a licenciatura que está cursando, atuará somente em atividades pedagógicas, em escolas públicas de educação infantil, ensino fundamental e ensino médio da educação básica, podendo atender também a jovens e adultos, pessoas com deficiências, comunidades quilombolas, indígenas e educação do campo (BRASIL, 2010a). 
O professor da licenciatura responsável pelo acompanhamento do bolsista é chamado de coordenador de área e terá as seguintes atribuições:

a) planejamento, organização e execução das atividades de iniciação à docência em sua área de atuação acadêmica;

b) acompanhamento, orientação e avaliação dos bolsistas estudantes de licenciatura; e

c) articulação e diálogo com as escolas públicas nas quais os bolsistas exerçam suas atividades (BRASIL, 2010a, artigo $2^{\circ}$, inciso III).

O professor da escola de educação básica para onde o bolsista for enviado é chamado de professor supervisor e deverá acompanhar e supervisionar as atividades de iniciação à docência que os bolsistas desenvolvem em sua unidade escolar.

Desta forma, o decreto prevê a ação conjunta entre estes professores: atuação dos estudantes bolsistas deverá ser planejada, acompanhada e avaliada pelos professores coordenadores e supervisores, em atendimento às disposições do projeto institucional" (BRASIL, 2010a, artigo 7º parágrafo único).

As unidades escolares participantes do programa serão escolhidas de acordo com o Índice de Desenvolvimento da Educação Básica (IDEB) ${ }^{1}$, para que as escolas com menores índices recebam apoio. Também podem fazer parte do programa escolas com experiências de ensino-aprendizagem bem sucedidas, a fim de que os licenciandos possam atuar em diferentes perspectivas (BRASIL, 2010a).

As instituições de ensino superior mantidas pelo poder público ou da iniciativa privada poderão enviar seus projeto à CAPES nos períodos de chamada pública, desde que possuam cursos de licenciatura devidamente legalizados. Caberá a estas instituições a organização de seminários de iniciação à docência, a fim de que sejam espaços de socialização dos conhecimentos construídos pelos bolsistas e de análise do impacto da sua atuação nas escolas. Os seminários deverão contar com a participação dos bolsistas e também dos professores coordenadores e supervisores, constituindo um esforço conjunto de avaliação das ações do programa.

Portanto, são objetivos do PIBID:

\footnotetext{
${ }^{1}$ O Índice de Desenvolvimento da Educação Básica (Ideb) foi criado pelo Inep em 2007 e representa a iniciativa pioneira de reunir em um só indicador dois conceitos igualmente importantes para a qualidade da educação: fluxo escolar e médias de desempenho nas avaliações. Ele agrega ao enfoque pedagógico dos resultados das avaliações em larga escala do Inep a possibilidade de resultados sintéticos, facilmente assimiláveis, e que permitem traçar metas de qualidade educacional para os sistemas. O indicador é calculado a partir dos dados sobre aprovação escolar, obtidos no Censo Escolar, e médias de desempenho nas avaliações do Inep, o Saebpara as unidades da federação e para o país, e a Prova Brasil- para os municípios. Disponível em: http://portal.inep.gov.br/web/portal-ideb/o-que-e-o-ideb. Acesso em 17 jul. 2015.
} 
I - incentivar a formação de docentes em nível superior para a educação básica;

II - contribuir para a valorização do magistério;

III - elevar a qualidade da formação inicial de professores nos cursos de licenciatura, promovendo a integração entre educação superior e educação básica;

IV - inserir os licenciandos no cotidiano de escolas da rede pública de educação, proporcionando-lhes oportunidades de criação e participação em experiências metodológicas, tecnológicas e práticas docentes de caráter inovador e interdisciplinar que busquem a superação de problemas identificados no processo de ensinoaprendizagem;

V - incentivar escolas públicas de educação básica, mobilizando seus professores como coformadores dos futuros docentes e tornando-as protagonistas nos processos de formação inicial para o magistério; e

VI - contribuir para a articulação entre teoria e prática necessárias à formação dos docentes, elevando a qualidade das ações acadêmicas nos cursos de licenciatura (BRASIL, 2010b, artigo $3^{\circ}$ ).

Em 2013, a portaria $n^{\circ} 096$ da CAPES acrescenta outro objetivo ao Programa: "contribuir para que os estudantes de licenciatura se insiram na cultura escolar do magistério, por meio da apropriação e da reflexão sobre instrumentos, saberes e peculiaridades do trabalho docente" (BRASIL, 2013b, artigo $4^{\circ}$, inciso VII), enfatizando a importância do licenciando vivenciar a realidade da escola brasileira e refletir sobre as situações presenciadas a partir do referencial teórico-prático construído ao longo de sua formação inicial.

Ainda que o PIBID receba críticas, especialmente por sua limitada abrangência no quadro geral das licenciaturas brasileiras, além do caráter instável de sua existência por ser uma política de governo e não Estado, seus objetivos parecem promissores de acordo com Gatti et al. (2014). Em estudo avaliativo realizado em âmbito nacional com licenciandos, supervisores, coordenadores institucionais e de área, estes pesquisadores constataram que o posicionamento dos participantes é significativamente favorável quanto ao programa.

Observou-se como o PIBID é valorizado em todos os níveis, por todos os participantes que responderam aos questionários. Os depoimentos são muito positivos, em sua imensa maioria; os detalhes oferecidos para justificar essa positividade são inúmeros e se expressam nas contribuições descritas (GATTI, ANDRÉ, GIMENES, FERRAGUT, 2014, p. 103).

Aos contornos deste trabalho, indica-se que a interação do licenciando com o 
cotidiano de professores experientes da educação básica pode constituir importante meio de análise das condições atuais da docência no país, o que deve ser aproveitado pela universidade, como evidenciado a seguir.

\section{O PIBID em Tempos de Desprofissionalização Docente}

Como abordado anteriormente, o fenômeno da desprofissionalização docente (MAROY, 2006; OLIVEIRA, 2010) caracteriza-se pelas dificuldades que as políticas educacionais atuais vêm trazendo ao cotidiano escolar, ao exercerem grande pressão sobre os atores envolvidos no processo ensino-aprendizagem, no sentido de priorizar os resultados das avaliações externas.

Assim, no contexto brasileiro, o governo federal e também os sistemas municipais e estaduais trabalham com formas de avaliação externa através de testes padronizados que classificam as escolas de acordo com os resultados obtidos por seus alunos nos testes realizados. Os resultados de uma destas avaliações externas, a Prova Brasil, constituem um dos indicadores de atribuição do IDEB, calculado para cada escola pública do território nacional. Esta alternativa quantitativa de avaliação baseia-se num padrão rígido de medição/controle das aprendizagens dos alunos e da atuação dos seus professores (ESTEBAN, 2003), trazendo sérias consequências à docência e à aprendizagem dos alunos.

A pressão por atingir metas que vêm de fora (de cima para baixo); a crescente introdução das tecnologias da informação e da comunicação na sala de aula, desafiando os professores a uma nova compreensão de desenvolvimento curricular (ALMEIDA; SILVA, 2011); a perda das legitimidades do mestre, que não goza mais do respeito social de outrora (DUBET, 2011); a precarização do ambiente e das condições de trabalho, bem como da remuneração oferecida ao magistério constituem alguns dos fatores reveladores do mal estar na docência.

Para os alunos, a ênfase na performance nos testes padronizados também não tem se mostrado promissora, pois, de acordo com Darling-Hammond e Ascher (2006), resultam na degradação da aprendizagem, na medida em que baseiam-se em práticas de transmissão de fragmentos de informações, no desenvolvimento de habilidades que podem ser contabilizadas, em detrimento daquelas que não o podem.

\footnotetext{
Ainda que o objetivo seja tornar os professores responsáveis pela qualidade da aprendizagem, determinados métodos voltados a este fim restringem as práticas escolares de tal forma que, na verdade, fazem com que os alunos aprendam menos. Em razão de tais complicações, não é de surpreender que os gestores de sistemas de ensino tenham freqüientemente recorrido à estratégia aparentemente mais fácil - o monitoramento dos estudantes por
} 
via de notas em testes -, e tenham até, eventualmente, ligado suas decisões fundamentais (promoções, graduações, premiações ou sanções de professores e escolas) aos resultados desses testes, provavelmente como meio de alcançar certa responsabilidade (DARLING-HAMMOND; ASCHER, 2006, p. 9-10).

Diante deste contexto, cabe à universidade atuar na formação de novos professores preparados para lidar com tais dificuldades, desenvolvendo uma postura crítica e de combate a todas as formas de desprofissionalização do trabalho docente e, consequentemente, de degradação da aprendizagem dos alunos.

Indica-se, neste trabalho, que atuando no cotidiano escolar sob a supervisão do professor da universidade e outro da escola de educação básica, o bolsista tem a oportunidade de se aproximar das questões aqui tratadas, refletindo a partir delas. Desta forma, a atuação no PIBID pode trazer significativas contribuições para a formação da atitude crítica dos bolsistas diante do quadro atual da docência, uma vez que terão outros momentos sistemáticos de contato com a escola, além do Estágio Supervisionado.

Para que isto se torne possível, destaca-se o necessário acompanhamento do professor do ensino superior, o coordenador de área, no sentido de propor questionamentos a partir das situações vivenciadas na prática do bolsista, colocando em discussão as políticas educacionais atuais, que trazem suas consequências ao cotidiano escolar, especialmente no que diz respeito às avaliações externas.

Segundo Lessard (2006):

[...] a universidade pode trazer uma contribuição significativa. Em teoria, ela é o lugar do pluralismo científico, da crítica e da prática da dúvida. Essas características tradicionais da universidade parecem essenciais para se evitar uma visão redutora do ensino e a dominação incontestada de uma ortodoxia profissional (LESSARD, 2006, p. 223).

Para a universidade, os seminários de iniciação à docência podem constituir momento significativo de discussão desta temática com as escolas de educação básica participantes do PIBID. Neste espaço, além da avaliação das ações do programa, a questão da intensificação do trabalho docente também pode ser abordada, gerando reflexão conjunta entre universidade e escola, no intuito de propor formas de combate a esta situação.

Assim, como abordado anteriormente, um objetivo do PIBID refere-se à intenção de ajudar o licenciando a inserir-se na cultura escolar do magistério, refletindo sobre o trabalho docente. Neste sentido, o papel da universidade se evidencia, na medida em que deve criar condições para que o bolsista se aproprie da cultura escolar, problematizando-a, sobretudo no 
que diz respeito à ênfase nos resultados das avaliações externas nas escolas públicas de educação básica.

Sobre estas avaliações externas, sabe-se que o PIBID se posiciona favoravelmente, uma vez que vincula a escolha da escola ao IDEB por ela apresentado. Ou seja, uma escola com IDEB baixo é tida coma necessitada de apoio, sendo o PIBID um meio de melhorar o índice da escola.

Segundo Silva (2012, p. 118), a partir de 2010, o PIBID deixa de vincular "que as atividades realizadas considerem a preparação para melhores desempenhos em avaliações externas à escola". Contudo, ainda permanece o critério de baixo IDEB para a escolha das escolas participantes do programa.

Gatti et al. (2014) perguntaram aos coordenadores institucionais se a participação no programa havia melhorado o IDEB da escola. Os pesquisadores explicam:

\begin{abstract}
Embora considerando que qualquer relação entre o desenvolvimento do programa e o desempenho dos alunos das escolas básicas participantes nas avaliações externas seja de difícil aferição, uma vez que há inúmeros outros fatores interagindo ao mesmo tempo no ambiente escolar, foi solicitado que os Coordenadores Institucionais declarassem se teriam registros de melhoria no Ideb nas escolas participantes do Pibid (GATTI, ANDRÉ, GIMENES, FERRAGUT, 2014, p. 78).
\end{abstract}

Os coordenadores institucionais em sua maioria, $60,5 \%$, responderam que não havia dados para responder a questão. Contudo, destaca-se o depoimento de um coordenador institucional do Centro Oeste:

[...] Do ponto de vista da mudança nas práticas escolares, outros fatores têm que ser trabalhados pela instituição MEC: piso salarial, condições de trabalho docente, infraestrutura das escolas, políticas de formação continuada etc. O Ideb é um índice que depende de fatores muito mais importantes que a ação pontual em um ou dois grupos do Pibid (GATTI, ANDRÉ, GIMENES, FERRAGUT, 2014, p. 93).

Neste trabalho, concorda-se com este depoimento, uma vez que as dificuldades enfrentadas pelas escolas advêm de vários âmbitos, como os citados acima. Políticas educacionais que atuem sobre estas dificuldades são imprescindíveis para as escolas e, especificamente, para o trabalho do professor.

Torna-se relevante ainda atentar à percepção dos licenciandos acerca do ensino pautado nos testes padronizados. Atuando no cotidiano escolar, podem constatar se o processo 
ensino-aprendizagem está voltado ao "treinamento" dos alunos visando o "sucesso" nos testes ou à construção de conhecimentos numa perspectiva crítica.

Segundo Rocha (2012), é exatamente neste ponto que se estabelece uma importante divergência entre a formação inicial de professores e os interesses da escola. Ao analisar uma experiência local do PIBID proposta pela UFES, o autor pondera que a contribuição do programa aos licenciandos consiste na possibilidade de experimentar a docência ainda na formação inicial. Assim, são necessárias atividades aproximadas à docência de fato, que propiciem aos licenciandos a reflexão permanente sobre os saberes necessários ao trabalho.

Neste sentido, o autor problematiza a demanda das escolas por aulas de reforço, claramente vinculadas à preocupação em elevar o IDEB apresentado pela unidade, o que para os licenciandos não constitui a experiência mais rica na docência, uma vez que as salas de aula não se assemelham às atividades propostas no reforço.

Rocha (2012) pondera:

\begin{abstract}
A contradição posta para os embates em torno da forma de organização da intervenção no PIBID está justamente nos interesses imediatos da escola. Se de um lado a contribuição fundamental do PIBID para a formação inicial é a intervenção em sala de aulas aproximando-se das atividades da docência para a produção do conhecimento pedagógico, de outro a pressão recebida pelas escolas (e os objetivos postos pela CAPES corroboram) pelo aumento do índice de Desenvolvimento da Educação Básica - IDEB, faz com que as escolas públicas atendidas pelo programa tenham como expectativa/prioridade da intervenção dos licenciandos no "reforço escolar". Como estabelecer medição necessária? A questão está posta para a CAPES e para os todos os projetos Institucionais (ROCHA, 2012, p. 21).
\end{abstract}

Desta forma, para que o programa consiga atuar significativamente na iniciação à docência, a problematização quanto às políticas educacionais torna-se necessária, não só no âmbito das licenciaturas, mas também nas escolas, inclusive pelas diferentes instâncias do poder público, como a CAPES.

Seria importante buscar coletivamente um novo sentido de avaliação, mais democrático (ESTEBAN, 2003), baseado em instrumentos avaliativos que estejam comprometidos com a real aprendizagem dos alunos, como:

[...] portfólios, exposições, demonstrações e outras avaliações baseadas no desempenho. Contrapondo-se aos testes padronizados de múltipla escolha, essas estratégias de avaliação apresentam problemas de estrutura defeituosa, o que exige dos estudantes um raciocínio analítico e uma demonstração de sua proficiência como se estivessem em uma situação problemática da vida real (DARLING-HAMMOND; ASCHER, 2006, p. 40). 
É certo que a formação de novos professores dotados de criticidade quanto às políticas educacionais vigentes não solucionará por si o problema, mas no quadro atual, torna-se fator importante. Neste contexto, o PIBID pode auxiliar o licenciando a refletir e questionar as políticas educacionais que vêm causando a desprofissionalização docente, levando-o a posicionar-se criticamente ao exercer o ofício. Destaca-se o relevante papel do coordenador de área neste processo desafiador.

\section{Considerações Finais}

Com as mudanças atuais nas políticas educacionais em vários países, a docência tem enfrentado tempos difíceis. No contexto brasileiro, este quadro não é diferente, o que preocupa os profissionais da educação, podendo levar ao mal estar no exercício do ofício, caracterizando o fenômeno de desprofissionalização docente.

O poder público tem intensificado o controle das instituições educacionais através das avaliações externas, que classificam as escolas por índices de desenvolvimento, gerando uma pressão sobre o professor para que os alunos alcancem os resultados desejados. Esta pressão também chega às licenciaturas, na medida em que repousa sobre estes cursos a responsabilidade de formar profissionais aptos a instruírem mão-de-obra preparada para o mercado de trabalho atual, a fim de garantir a competitividade econômica do país.

Neste cenário, surge uma política de incentivo à formação inicial de professores, o PIBID (Programa Institucional de Bolsa de Iniciação à Docência), que possibilita a presença remunerada do licenciando no cotidiano escolar, exercendo atividades pedagógicas junto a alunos da escola de educação básica, sendo acompanhado por um professor da licenciatura e outro da escola, que também recebem bolsa. Esta remuneração permite maior envolvimento dos participantes, o que pode beneficiar também os alunos da educação básica atendidos pelo bolsista.

Neste trabalho, objetivou-se refletir sobre o PIBIB, no contexto atual de desprofissionalização docente. Evidenciou-se que o programa conta com uma avaliação muito positiva de seus participantes. Entretanto, por se tratar de uma política pública federal, o PIBID está vinculado ao IDEB e, por isso, pode haver uma demanda, por parte das escolas, de que suas atividades auxiliem na melhoria do índice.

Assumiu-se, neste trabalho, que a atuação do PIBID junto à escola para auxiliá-la a pensar seu próprio processo de ensino-aprendizagem vem se mostrando significativa. $\mathrm{O}$ programa parece favorecer as aprendizagens dos alunos da educação básica, a formação inicial do licenciando e a formação contínua do professor da educação básica e da licenciatura. 
Desconfia-se, porém, de iniciativas pibidianas de reforço escolar que mais parecem "treinamento" para as avaliações externas, objetivando a melhoria do IDEB da escola. Tais iniciativas limitariam a iniciação à docência do licenciando e podem não ser um meio de aprendizagem significativa por parte dos alunos da escola.

Destaca-se o papel da universidade, na figura do coordenador de área, ao fomentar a reflexão do licenciando, do supervisor e da comunidade escolar sobre o contexto atual da docência, permeado de políticas educacionais interferindo no trabalho docente. Indica-se, portanto, que o PIBID pode constituir um espaço de reflexão, sendo um meio de problematização da docência na contemporaneidade.

\section{Referências}

ALMEIDA, M. E.; SILVA, M. G. M. Currículo, tecnologia e cultura digital: espaços e tempos de web currículo. Revista e-curriculum, v.7, n.1, p.1-19, abr/2011.

BRASIL, Decreto $\mathrm{n}^{\circ} 7.219$, de 24 de junho de 2010a. Dispõe sobre o Programa Institucional de Bolsa de Iniciação à Docência- PIBID e dá outras providências. Diário Oficial da União. Brasília: Casa Civil. Disponível em: 〈http://www.capes.gov.br/educacao-basica/capespibid> Acesso em: jan. 2013.

BRASIL, Parecer $n^{\circ} 260$, de 30 de dezembro de 2010b. Normas Gerais do Programa Institucional de Bolsa de Iniciação à Docência- PIBID. Disponível em: <http://www.capes.gov.br> Acesso em: jan. 2013.

BRASIL. CAPES/DEB. Relatório de Gestão 2009-2013. Brasília: 2013a. Disponível em: https://www.capes.gov.br/images/stories/download/bolsas/2562014-relatrorio-DEB-2013web.pdf. Acesso em 22 jul. 2015.

BRASIL, Parecer n 096, de 18 de julho de 2013b. Regulamento do Programa Institucional de Bolsa de Iniciação à Docência- PIBID. Disponível em: <http://www.capes.gov.br> Acesso em: set. 2013.

DARLING-HAMMOND, L.; ASCHER, C. Construindo sistemas de controle em escolas urbanas. Estudos em Avaliação Educacional, v. 17, no 35, p. 7-48, set/dez 2006.

DUBET, F. Mutações cruzadas: a cidadania e a escola. Revista Brasileira de Educação, vol. 16, n. 47, p. 289-305, mai/ago 2011.

ESTEBAN, M. T. (Org). Avaliação: uma prática em busca de novos sentidos. 4.ed. Rio de Janeiro: DP\&A, 2003. 142 p.

GATTI, B. A. Formação de professores no Brasil: características e problemas. Educação e Sociedade, Campinas, v. 31, n. 113, p. 1355-1379, out./dez. 2010.

Formação Inicial de Professores para a Educação Básica: Pesquisas e Políticas Educacionais. Estudos em Avaliação Educacional., São Paulo, v. 25, n. 57, p. 24-54, 
jan./abr. 2014.

; BARRetO, E. S. S.; ANDRÉ, M. E. D. A. Políticas Docentes no Brasil. Brasília: UNESCO, 2011.

; ANDRE, M. E. D.; GIMENES, N. A. S.; FERRAGUT, L. Um estudo avaliativo do Programa Institucional de Bolsa de Iniciação à Docência (PIBID). Coleção Textos FCC, v. 41, p. 4-117, 2014.

LANTHEAUME, F. Professores e dificuldades do ofício: preservação e reconstrução da dignidade profissional. Cadernos de Pesquisa, v. 42, nº 146, p.368-387, maio/ago. 2012.

LELIS, I. O trabalho docente na escola de massa: desafios e perspectivas. Sociologias, Porto Alegre, ano 14, no 29, jan./abr., p. 152-174, 2012.

LESSARD, C. A universidade e a formação profissional dos docentes: novos questionamentos. Educação e Sociedade, v. 27, nº 94, p. 201-227, jan/abr. 2006.

MAROY, C. Les évolutions du travail enseignant en France et en Europe: facteurs de changement, incidences et résistances dans l'enseignement secondaire. Revue Française de Pédagogie, $\mathrm{n}^{\mathrm{o}}$ 155, p. 111-142, avril/juin 2006. Disponível em: <http://rfp.revues.org/273?lang=en>. Acesso em: jul. 2013.

OLIVEIRA, D. A. Os Trabalhadores da Educação e a construção política da profissão docente no Brasil. Educar em Revista, Curitiba, Brasil, N. Especial 1, p. 17-35, 2010.

ROCHA, L. A. O. O PIBID Linguagens e a Formação de Professores: princípios, ações e reflexões. In: XVI Encontro Nacional de Didática e Práticas de Ensino- ENDIPE, 2012, Campinas-SP. Didática e Prática de Ensino: compromisso com a escola pública, laica, gratuita e de qualidade. Araraquara, SP: Junqueira\&Marin, v. 2, 2012.

SILVA, A. A. Repercussões das atividades desenvolvidas pelos Projetos Institucionais da UFSM no âmbito do PIBID/CAPES/MEC em Escolas Públicas de Educação Básica. Mestrado Acadêmico: Universidade Federal de Santa Maria, 2012.

Recebido em: 15/02/2014

Revisado em: 24/07/2015

Aprovado para publicação em: 31/07/2015

Publicado em: 30/04/2016 